\title{
Morphometric analysis of some metric characters of two Macrobiotus species (Eutardigrada, Macrobiotidae)
}

\author{
Giovanni PILATO*, Giovanni COSTA, Erminia CONTI, Maria Grazia BINDA and Oscar LISI \\ Department of Animal Biology "Marcello La Greca", University of Catania, Via Androne 81, 95124 Catania, Italy \\ *e-mail corresponding author: pilato@unict.it
}

\begin{abstract}
A study on individual variability was carried out on some metric characters of two species of Eutardigrada Macrobiotidae: Macrobiotus diffusus and Macrobiotus areolatus. Other than range of variability for various characters considered, correlation analysis and regression analysis for some of them were carried out by means of binary comparisons. By means of prediction ellipses, which were always determined with a probability of $\mathrm{P}=99.9 \%$, it was possible to hypothesize - with an error risk of $0.1 \%$ - if an individual whose data were outside the confidence interval belonged to a species. The value of the pt index relative to the point of insertion of the stylet supports is particularly significant, showing variations with extremely limited and independent dispersion both for body length and for buccal tube length.
\end{abstract}

Key words: Tardigrada, Eutardigrada, Macrobiotus, metric characters, intraspecific variability

\section{INTRODUCTION}

A correct, specific diagnosis is obviously essential not only in taxonomical studies but also in a study of any aspect of an organism's biology. This diagnosis necessitates the knowledge of the range of intraspecific variability of characters taken into consideration. Traditionally it was thought that in all limno-terrestrial tardigrades individual variability was large. This belief created a vicious circle. Believing that intraspecific variability was large, many authors combined, and some still do, populations from multiple species. This presents an illusion of even greater variability which further complicates the problem. The situation becomes even more confusing when species differ especially for metric characters.

Since 1969 though, and particularly from the research of Pilato $(1969,1972,1973,1974 a, b, 1975$, 1981), Binda (1974, 1988), Pilato et al. (1982) and Pilato \& Binda (1983), something began to change, as it was shown that, contrary to tradition, many characters of those animals do not have a large intraspecific variability; however, their variability is very restricted (Bertolani 1976, 1979, 1982; Greven 1977; Maucci 1979, 1986; Kristensen 1982, 1987; Ramazzotti \& Maucci 1982; Bertolani \& Kristensen 1987; Manicardi \& Bertolani 1987; Dastych 1988; Biserov 1988; Bertolani \& Balsamo 1989).

Pilato $(1972,1973,1974 a, b)$ particularly studied the variability of the buccal armature in some species of Macrobiotus and Isohypsibius, and he also showed (1981) the limited intraspecific variability of the level of insertion of the stylet supports on the buccal tube expressed as the $p t$ index, that is as a percentage of the length of the surely rigid portion of the buccal tube (etymology of $p t$ : percentage of the buccal tube). This assertion was confirmed by Pilato et al. (1982). This character is now used by all specialists. In 1979 Pilato also provided an explanation of the fact that individual variability in limno-terrestrial tardigrades is very low: this was based on their biology.

Unfortunately, there is no statistical study on the range of the variability of the various characters and thus, in many cases, there are still doubts that are difficult to eliminate. Recognition must be given to Ramazzotti (1977) who, studying a population of Macrobiotus areolatus Murray, 1907, one sample gathered in the summer and another gathered in the winter, demonstrated that in both cases there exists a correlation between length and width of the buccal tube, and between each of these dimensions and body length. There also exists a correlation between the diameter of the eggs excluding the projections and the diameter of the eggs including these structures.

Schuster et al. (1978) found a direct proportional relationship between buccal tube length and body length for Dactylobiotus grandipes (Schuster, Toftner \& Grigarick, 1978).

Wainberg \& Hummon (1981) studied the variability of some characters of Isohypsibius saltursus Schuster, Nelson \& Grigarick, 1978 showing the linear regression between the dimensions of some structures (length of the whole buccal-pharyngeal apparatus, only of the buccal tube, buccal tube width, and claw length) and body length, and gave values of the intercept and slope of regression lines. Some data of this study are not very useful - for example the orientation of the claws was not specified by the authors. In regard to the buccalpharyngeal apparatus, it is known that the pharyngeal 
bulb is very deformable. In measuring the length of the buccal tube, Wainberg \& Hummon (1981) included the buccal cavity. The buccal cavity is connected to the buccal tube by means of a tract with flexible walls. When it flexes, the total length of the buccal tube is modified. In fact, the authors measured the same specimens before and after mounting them on slides and found differences in the total length of the buccalpharyngeal apparatus and in the length of the buccal tube. To avoid these discrepancies Pilato (1981) introduced the use of measuring only the clearly defined, rigid portion of the buccal tube; that is, the tract between the medio-dorsal crest of the buccal armature (or, if this is absent, between the anterior margin of the stylet sheaths) and the base of the pharyngeal apophyses.

Kinchin (1996) provided some data on the intraspecific variability of Ramazzottius varieornatus Bertolani \& Kinchin, 1993 and measured the buccal tube as indicated by Pilato (1981).

Kathman \& Nelson (1987) in Pseudobiotus augusti (Murray, 1907) found buccal tube length is not directly proportional to body length in specimens at least 350 $\mu \mathrm{m}$ long. To collect the animals, they had used a sieve with a mesh of $120 \mu \mathrm{m}$; consequently, many small specimens were not collected. Kathman \& Nelson (1987, p. 165) wrote: "However, use of a smaller mesh sieve (e.g. $63 \mu \mathrm{m}$ instead of $120 \mu \mathrm{m})$ would have captured more of the smaller, first instar animals, and perhaps a direct relationship between buccal tube length and body length (up $350 \mu \mathrm{m}$ ) would have been evident if these smaller juveniles had been collected". Also, Kathman \& Nelson (1987, p. 158) measured the buccal tube length "from the anterior to the posterior margin". This seems to indicate that they measured not only the rigid portion of the buccal tube but also the buccal cavity.

Kristensen \& Hallas (1980) found similar results in the heterotardigrade Echiniscoides sigismundi groenlandicus Kristensen \& Hallas, 1980; whereas in Echiniscoides hoepneri Kristensen \& Hallas, 1980, they found a direct relationship between the buccal tube length and the body length.

Given the scarcity of data available, we wanted to specifically study the intraspecific variability of the length and the width of the buccal tube and the insertion point of the stylet supports on the buccal tube in Macrobiotus diffusus Binda \& Pilato, 1987 and M. areolatus. The aim of this study is not to compare these two species (that are well distinguishable from one another for qualitative characters) but to demonstrate with statistical methods that the intraspecific variability of some metric characters is not very large, and to know the range of this variability. We think it is most useful to extend this study to other species because when the range of variability of some characters becomes known, metric characters will be useful for specific diagnosis. On one hand it is not excluded that many species have similar metric characters, but on the other hand it is not excluded that species similar to one another for qualitative characters, are different for metric characters. In any case metric characters may be used as specific characters, and may be significant, only when the range of their intraspecific variability is well known. Our choice to initiate this project studying Macrobiotus diffusus and M. areolatus is merely due to the fact that they are well known species; therefore, we can be sure of the specific characteristics. Also, we have many specimens collected from different localities and in different seasons.

Obviously, the absolute value of the dimensions of any structure varies with body growth. In comparison, this value has little significance if not compared to specimens of the same length. If, on the other hand, one knows the correlation between the length of various non-deformable structures and the length of the body of known species, then it is possible to compare these characters, both to specimens of various body sizes and to those specimens whose body lengths are not precisely measurable.

\section{METHODS}

We considered the species $M$. diffusus and $M$. areolatus. The first sampling, 96 specimens (Tab. 1), was from nine sites; the second, 109 specimens, was from ten sites.

As each species is concerned, our preliminary comparisons demonstrated that the studied populations are not distinguishable from one another for both qualitative and metric characters, and therefore are attributable to the same species.

We did not take care to distinguish between amphimictic and parthenogenetic strains, both because no one has reported distinctive morphological characters and because we wanted to have a good idea about variability working with a large number of populations. For the same reasons we collected many moss samples from different localities in different seasons and we disregarded sex and age of individual specimens.

From the various specimens of the two species, we examined the following metric characters: (a) BOLE = Body length; (b) BTLE = Buccal tube length; (c) BTWI $=$ Buccal tube width; (d) PtWI $=p t$ index relative to the width of the buccal tube; and (e) PtSTYL $=p t$ index relative to the insertion point of the stylet supports. The unit of measurement for body length, buccal tube length, and buccal tube width is $\mu \mathrm{m}$.

By applying binary comparisons we completed the analyses for correlation and linear regression between the characters indicated in table 2.

The various regression lines and prediction ellipses at $99.9 \%$ are represented graphically using STATISTICA software. This type of ellipse is useful for establishing confidence intervals for prediction of single new observations (prediction intervals). 
Tab. 1. Data relative to the sampling of Macrobiotus diffusus and Macrobiotus areolatus.

\begin{tabular}{|c|c|c|c|}
\hline \multicolumn{2}{|c|}{ Macrobiotus diffusus } & \multicolumn{2}{|c|}{ Macrobiotus areolatus } \\
\hline Site & $\mathrm{N}$ of specimens & Site & $\mathrm{N}$ of specimens \\
\hline Moio Alcantara (Nebrodi Mts) & 8 & Gorfigliano (Apuane Alps) & 4 \\
\hline Salina (Aeolian islands) & 50 & Serra del Prete (Lucania) & 16 \\
\hline Lipari (Aeolian islands) & 6 & Sorgenti su Cologone (Sardinia) & 12 \\
\hline Filicudi (Aeolian islands) & 2 & Monte Pollino (Sila) & 8 \\
\hline Island of Ustica & 3 & Panarea (Aeolian islands) & 14 \\
\hline Marettimo (Egadi islands) & 2 & Pian della Battaglia (Madonie) & 16 \\
\hline Vendicari (Siracusa) & 21 & Randazzo (Etna) & 14 \\
\hline Ain Draham (Tunisia) & 2 & Guardia Mangano (Catania) & 8 \\
\hline Barce (Libya) & 2 & Melilli (Siracusa) & 6 \\
\hline & & Cava del Carosello (Noto) & 11 \\
\hline TOTAL & 96 & TOTAL & 109 \\
\hline
\end{tabular}

Tab. 2. List of compared characters.

\begin{tabular}{ll}
\hline Body Length $v s$ Buccal Tube Length & BOLE $v s$ BTLE \\
Body Length $v s$ Buccal Tube Width & BOLE $v s$ BTWI \\
Body Length $v s t$ Buccal Tube Width & BOLE $v$ PtWI \\
Body Length $v s p t$ Stylet Supports & BOLE $v$ Pt STYL \\
Buccal Tube Length $v s$ Buccal Tube Width & BTLE $v s$ BTWI \\
Buccal Tube Length $v s$ Pt Stylet Supports & BTLE $v s$ Pt STYL \\
\hline
\end{tabular}

Body length was measured excluding the hind legs. Buccal tube length was measured (Fig. 1) from the medio-dorsal crest of the buccal armature at the base of the pharyngeal apophyses. Buccal tube width, including the width of the walls, was measured immediately behind the stylet insertion point. Stylet insertion point was considered the central point of contact between the stylet support and the wall of the buccal tube.

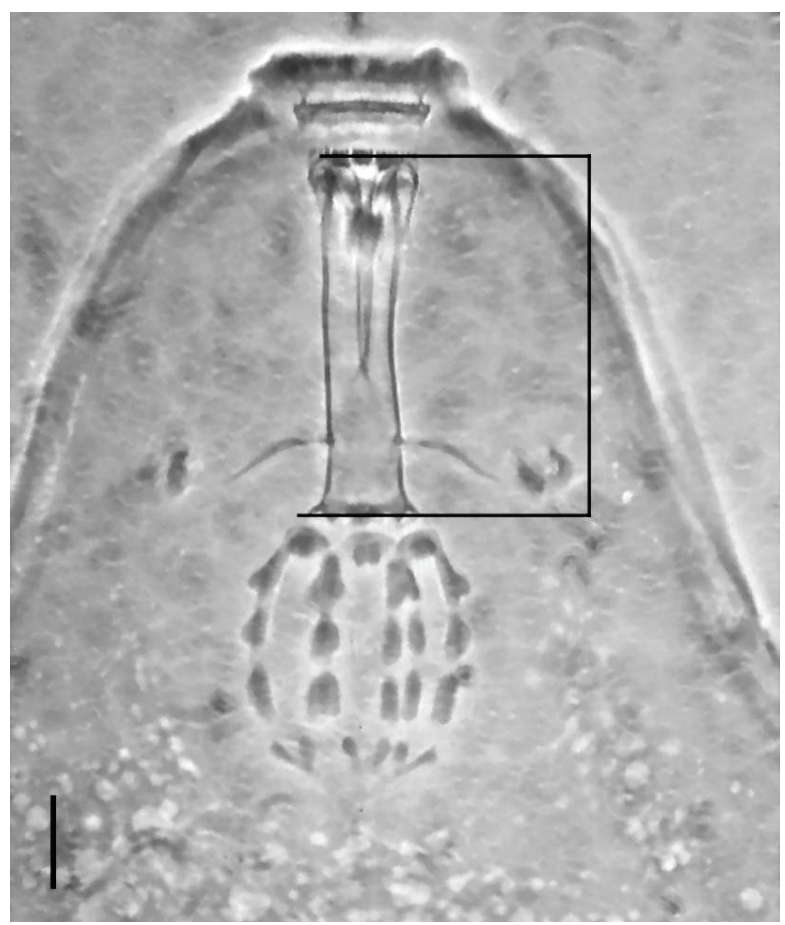

Fig. 1. Bucco-pharyngeal apparatus of Macrobiotus diffusus. The portion of the buccal tube is indicated which must be measured to calculate buccal tube length, and therefore the percentage ratio $p t$ relative to various structures. Scale bar $=10$ $\mu \mathrm{m}$.

\subsection{Statistical methodology}

For each of these characters, the classic statistical parameters were measured, namely: arithmetic mean $(\mathrm{m})$; minimum value ( $\mathrm{min})$; maximum value (max); standard deviation (SD); standard error (SE); and interval $\mathrm{m} \pm 3 \mathrm{SD}$.

This interval assumes a particular statistical importance in that it expresses the range within which all (with a probability of $99.9 \%$ ) values of various corresponding theoretical distributions fall.

The normality of the theoretical distributions relative to the metric characters considered was measured with the Kolmogorov-Smirnov goodness of fit test $(K-S d)$ (Zar 1974).

The significance of the coefficient of correlation $r$ was measured by the $t_{r}$ Student test. The significance of the slope $(b)$ of the regression line was evaluated using the procedure of variance analysis and the calculation of the relative value $F$ ( $F$-test). The coefficient of determination $r^{2}$ was also calculated to evaluate the efficiency of the fitted regression.

\section{RESULTS}

Table 3 shows the values of various statistical parameters calculated for each of the two species and for each of the metric characters considered. All distributions are normal.

The analysis of the correlation led to values of correlation coefficient always extremely significant, which are reported for the two species in table 4 together with the values of the $t_{r}$ test.

In the same table coefficients $a$ and $b$ of the regression lines, as well as the values of the $F$ test, are included. 
Tab. 3. Values of the statistical parameters relative to the metric characters considered for the two species under study.

\begin{tabular}{|c|c|c|c|c|c|}
\hline \multicolumn{6}{|c|}{ Macrobiotus diffusus $(\mathrm{n}=96)$} \\
\hline Stat. parameter & BOLE & BTLE & BTWI & PtWI & PtSTYL \\
\hline $\mathrm{m}$ & 272.72 & 33.89 & 6.49 & 19.07 & 78.27 \\
\hline $\min$ & 176.00 & 24.20 & 4.30 & 15.90 & 75.90 \\
\hline $\max$ & 370.00 & 41.50 & 8.60 & 21.70 & 79.90 \\
\hline SD & 43.20 & 3.67 & 0.97 & 1.32 & 0.87 \\
\hline $\mathrm{SE}$ & 4.41 & 0.37 & 0.10 & 0.13 & 0.09 \\
\hline K-S d & $0.08 ; \mathrm{P}>0.20$ & $0.12 ; \mathrm{P}>0.10$ & $0.10 ; \mathrm{P}>0.20$ & $0.09 ; \mathrm{P}>0.20$ & $0.09 ; \mathrm{P}>0.20$ \\
\hline $\mathrm{m}-3 \mathrm{SD}$ & 143.12 & 22.88 & 3.58 & 15.11 & 75.66 \\
\hline $\mathrm{m}+3 \mathrm{SD}$ & 402.32 & 44.90 & 9.40 & 23.03 & 80.88 \\
\hline \multicolumn{6}{|c|}{ Macrobiotus areolatus $(\mathrm{n}=109)$} \\
\hline Stat. parameter & BOLE & BTLE & BTWI & PtWI & PtSTYL \\
\hline $\mathrm{m}$ & 352.70 & 41.07 & 8.50 & 20.48 & 78.36 \\
\hline $\min$ & 175.00 & 25.00 & 4.60 & 15.60 & 76.10 \\
\hline $\mathrm{ax}$ & 536.00 & 56.70 & 14.80 & 26.10 & 80.40 \\
\hline SD & 79.41 & 6.38 & 2.04 & 2.37 & 0.88 \\
\hline SE & 7.61 & 0.61 & 0.20 & 0.23 & 0.08 \\
\hline K-S d & $0.10 ; \mathrm{P}>0.20$ & $0.10 ; \mathrm{P}>0.20$ & $0.06 ; P>0.20$ & $0.07 ; \mathrm{P}>0.20$ & $0.06 ; \mathrm{P}>0.20$ \\
\hline $\mathrm{m}-3 \mathrm{SD}$ & 114.47 & 21.93 & 2.38 & 13.37 & 75.72 \\
\hline $\mathrm{M}+3 \mathrm{SD}$ & 590.93 & 60.21 & 14.62 & 27.59 & 81.00 \\
\hline
\end{tabular}

Tab. 4. Analysis of the correlation and linear regression between the characters. $r=$ coefficient of correlation; $t_{r}=$ Student's $t$ test value for the significance of $r ; a=$ intercept of the regression line; $b=$ slope of regression line; $F=F$ test value for the significance of $b ; r^{2}=$ coefficient of determination. n.s. $=$ not significant; $*: P=0.95 ; * * *: P=0.0001$.

\begin{tabular}{|c|c|c|c|c|c|c|}
\hline \multicolumn{7}{|c|}{ Macrobiotus diffusus } \\
\hline Characters & $r$ & $t_{r}$ & $a$ & $b$ & $F$ & $r^{2}$ \\
\hline BOLE $v s$ BTLE & 0.92 & $22.13 * * *$ & 12.69 & 0.08 & $57.31 * * *$ & 0.85 \\
\hline BOLE vs BTWI & 0.85 & $15.65 * * *$ & 1.26 & 0.02 & $28.66 * * *$ & 0.72 \\
\hline BOLE vs PtWI & 0.44 & $4.79 * * *$ & 15.38 & 0.01 & 2.68 n.s. & 0.19 \\
\hline BOLE vs PtSTYL & 0.36 & $3.70 * * *$ & 76.31 & 0.007 & 1.60 n.s. & 0.13 \\
\hline BTLE $v s$ BTWI & 0.92 & $22.27 * * *$ & -1.78 & 0.24 & $58.04 * * *$ & 0.85 \\
\hline BTLE $v s$ PtSTYL & 0.41 & $4.32 * * *$ & 74.99 & 0.01 & 2.18 n.s. & 0.17 \\
\hline \multicolumn{7}{|c|}{ Macrobiotus areolatus } \\
\hline Characters & $r$ & $t_{r}$ & $a$ & $b$ & $F$ & $r^{2}$ \\
\hline BOLE $v s$ BTLE & 0.92 & $24.42 * * *$ & 14.97 & 0.07 & $61.30 * * *$ & 0.85 \\
\hline BOLE vs BTWI & 0.84 & $15.82 * * *$ & 0.93 & 0.02 & $25.71 * * *$ & 0.71 \\
\hline BOLE vs PtWI & 0.51 & $6.20 * * *$ & 15.07 & 0.02 & $3.96^{*}$ & 0.26 \\
\hline BOLE vs PtSTYL & 0.28 & $3.03 * * *$ & 77.27 & 0.003 & 0.94 n.s. & 0.08 \\
\hline BTLE vs BTWI & 0.91 & $22.63 * * *$ & -3.42 & 0.29 & $52.65 * * *$ & 0.83 \\
\hline BTLE $v s$ PtSTYL & 0.33 & $3.63 * * *$ & 76.49 & 0.05 & 1.35 n.s. & 0.11 \\
\hline
\end{tabular}

As indicated, there is an extreme significance $(P$ $<0.001$ ) of coefficient $b$ in comparisons between BTLE and BOLE, between BTWI and BOLE, and between BTWI and BTLE for both species; in $M$. areolatus there is a significance $(P<0.05)$ also for PtWI vs BOLE; while there is no significance for $P<0.05$ in the other cases. It can be seen that in all comparisons in which the character PtSTYL is involved, significance of coefficient $b$ was never obtained; this fact indicates that variations of values for the $p t$ index relative to the stylet supports are independent of both body length and variations of buccal tube length. The current finding, with limited variability, makes this character very interesting for specific diagnoses.
In figures 2-7 regression lines are shown, independently of the significance of their slopes, and prediction ellipses.

\section{CONCLUSIONS}

This study of individual variability of some characters, and eventually concerning other ones, shows that it would be useful to apply it to all species because the knowledge of the individual variability would allow, in the cases of significant differences, to exclude from a species specimens that, due to their qualitative characters, are similar to it. 

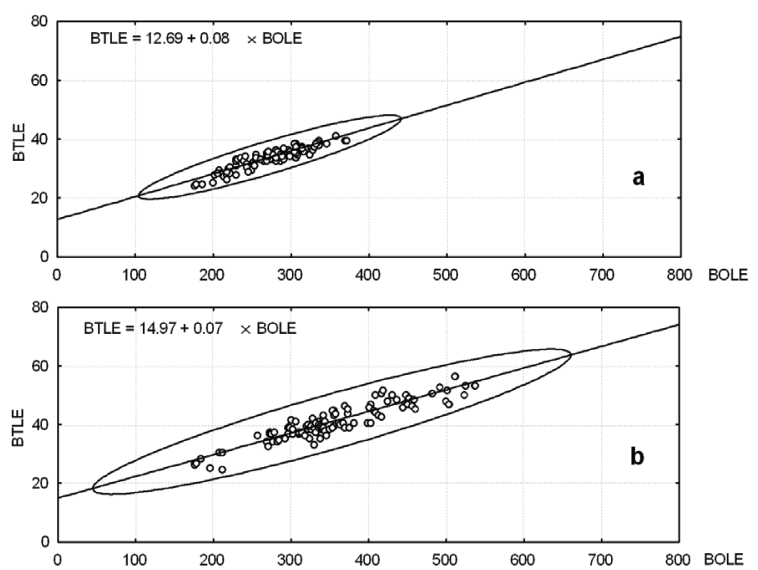

Fig. 2. Regression line between BOLE and BTLE. a: Macrobiotus diffusus; $\mathbf{b}$ : Macrobiotus areolatus. The ellipse of confidence for a probability of $99.9 \%$ is shown. The unit of measurement is $\mu \mathrm{m}$.
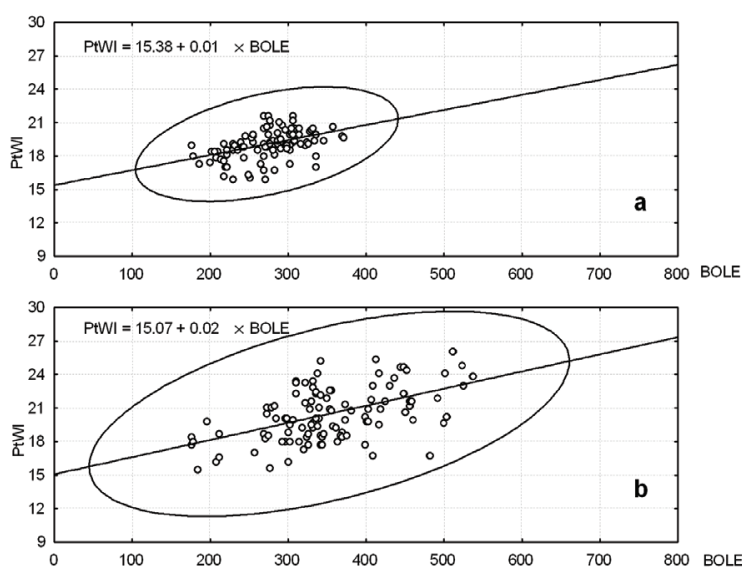

Fig. 4. Regression line between BOLE and PtWI. a: Macrobiotus diffusus; b: Macrobiotus areolatus. The ellipse of confidence for a probability of $99.9 \%$ is shown. The unit of measurement of body length is $\mu \mathrm{m}$.
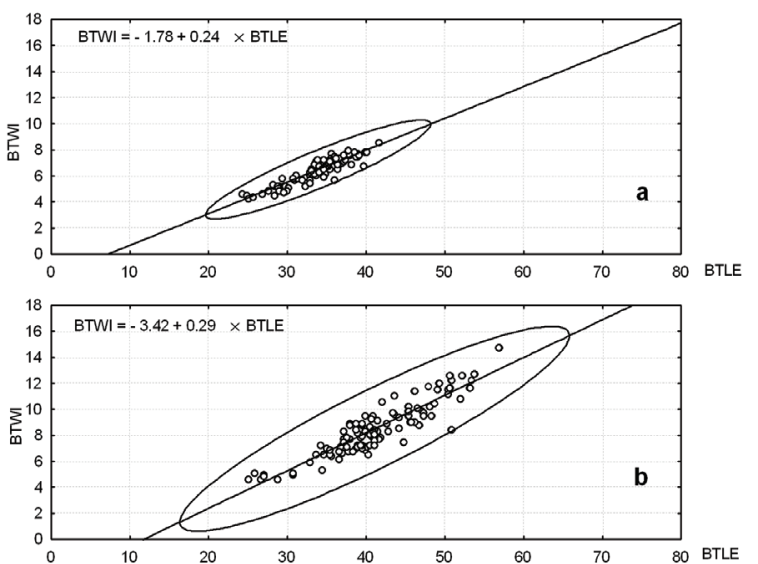

Fig. 6. Regression line between BTLE and BTWI. a: Macrobiotus diffusus; $\mathbf{b}$ : Macrobiotus areolatus. The ellipse of confidence for a probability of $99.9 \%$ is shown. The unit of measurement is $\mu \mathrm{m}$.
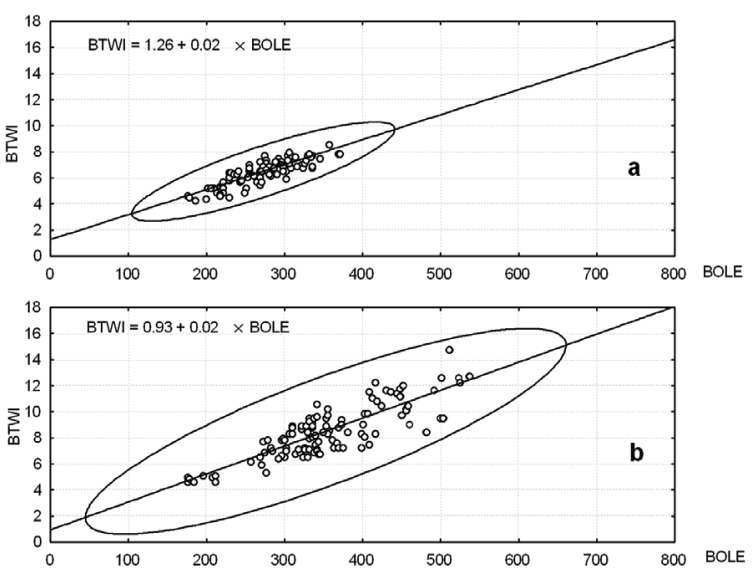

Fig. 3. Regression line between BOLE and BTWI. a: Macrobiotus diffusus; b: Macrobiotus areolatus. The ellipse of confidence for a probability of $99.9 \%$ is shown. The unit of measurement is $\mu \mathrm{m}$.
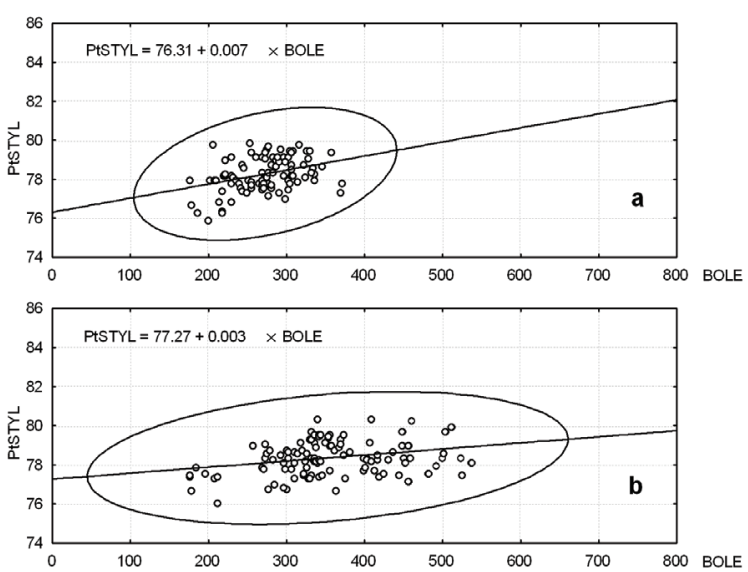

Fig. 5. Regression line between BOLE and PtSTYL. a: Macrobiotus diffusus; b: Macrobiotus areolatus. The ellipse of confidence for a probability of $99.9 \%$ is shown. The unit of measurement of body length is $\mu \mathrm{m}$.
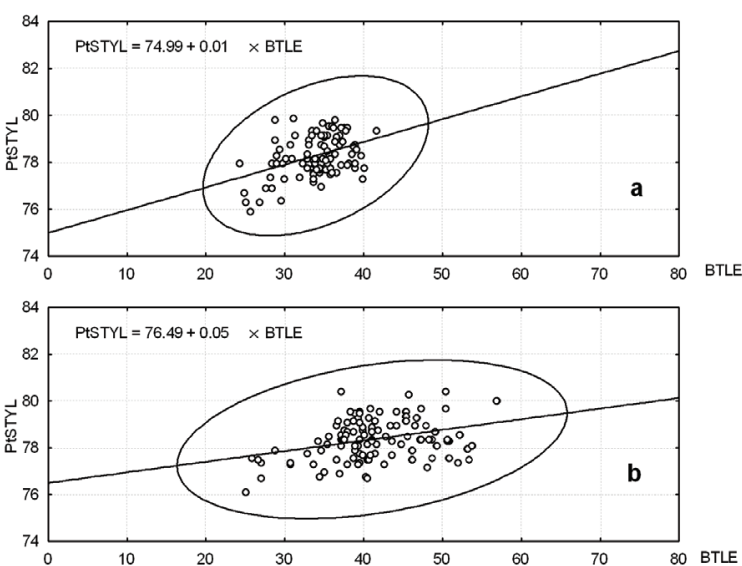

Fig. 7. Regression line between BTLE and PtSTYL. a: Macrobiotus diffusus; b: Macrobiotus areolatus. The ellipse of confidence for a probability of $99.9 \%$ is shown. The unit of measurement of buccal tube length is $\mu \mathrm{m}$. 
As stated before, if we do not know how the dimensions of a structure vary with body size, we could only compare specimens of the same body size; in fact, in the absence of this information we cannot establish whether eventual differences in size of a structure are included in individual variability of a species or are indices of membership of another species.

Dimensions of a structure that a specimen should have if it belonged to a determined species can be calculated when: (a) limits of the variability of the dimensions of various structures of a known species have been identified, (b) dimensional variation with respect to each other (in particular with respect to body length and to a rigid, non-deformable structure such as the buccal tube) has been established, and (c) the dimension of one structure is known. By knowing the prediction ellipses, we can evaluate whether or not dimensions of structures, either in a population or in a single specimen, are compatible with the membership of specimens studied in a particular known species.

In fact, if the dimensions of a structure of the specimens studied fall outside the relative prediction ellipses of known species, we have just $0.1 \%$ probability of error if we deny membership to that species. Obviously, the compatibility does not necessarily mean that they belong to the same species, given that we cannot exclude the existence of different species with an identical character.

Therefore, prediction ellipses may be useful statistical tools for assessing the compatibility of values for metric characters of an individual with the range of variability of these characters in known species.

The $p t$ index value relative to the insertion point of stylet supports is a particularly useful character. In both species studied on this occasion, values of this index showed a rather limited intraspecific variability, and are independent from variations of body length and from length of the buccal tube. These results completely confirm what was stated by Pilato (1981) and by Pilato et al. (1982) for Isohypsibius elegans Binda \& Pilato, 1971.

In conclusion, from this study it appears certain that analysis of metric characters of limno-terrestrial tardigrades, extremely poor up to now, is a tool that can make specific diagnosis easier and more exact. In particular, it can be useful in distinguishing species that are very similar, or even indistinguishable, if based only on qualitative characters.

\section{REFERENCES}

Bertolani, R. 1976. Osservazioni cariologiche su Isohypsibius augusti (Murray, 1910) e I. megalonyx Thulin, 1928 (Tardigrada) e ridescrizione delle due specie. Boll. Zool., 43: 221-234.

Bertolani, R. 1979. Parthenogenesis and cytotaxonomy in Itaquasconinae (Tardigrada). Zesz. Nauk. Uniw. Jagellon., Prace Zool., 25: 9-18.

Bertolani, R. 1982. Cytology and reproductive mechanisms in Tardigrada. In: D.R. Nelson (Ed.), Proc. Third Int. Sympo- sium on Tardigrada. East Tennessee State University Press, Johnson City, Tennessee, USA: 93-114.

Bertolani, R. \& M. Balsamo. 1989. Tardigradi e Gastrotrichi del Trentino, il Lago di Tovel. Studi Trentini di Sci. Nat., 65: 83-93

Bertolani, R. \& R.M. Kristensen. 1987. New record of Eohypsibius nadjae Kristensen, 1982, and revision of the taxonomic position of two genera of Eutardigrada (Tardigrada). In: R. Bertolani (Ed.), Biology of Tardigrades. Selected Symposia and Monographs, U.Z.I.,1. Mucchi Editore, Modena, Italy: 359-372.

Binda, M.G. 1974. Tardigradi della Valtellina. Animalia, 1: 201-216.

Binda, M.G. 1988. Ridescrizione di Macrobiotus echinogenitus Richters, 1904 e sul valore di buona specie di Macrobiotus crenulatus Richters, 1904 (Eutardigrada). Animalia, 15: 201-210.

Biserov, V. 1988. Limnetic Tardigrades of some areas in the USSR. Zool. Z., 67: 1798-1811.

Dastych, H. 1988. The Tardigrada of Poland. Monografie Fauny Polski, Polska Akad. Nauk., 16: 1-255.

Greven, H. 1977. Isohypsibius granulifer Thulin, 1928, ein neuer Tardigrade fur Deutschland. Decheniana, 130: 128-138.

Kathman, R.D. \& D.R. Nelson. 1987. Population trends in the aquatic tardigrade Pseudobiotus augusti (Murray). In: R. Bertolani (Ed.), Biology of Tardigrades. Selected Symposia and Monographs, U.Z.I.,1. Mucchi Editore, Modena, Italy: 155-168.

Kinchin, I.M. 1996. Morphometric analysis of Ramazzottius varieornatus (Hypsibiidae: Eutardigrada). Zool. J. Linn. Soc. London, 116: 51-60.

Kristensen, R.M. 1982. New aberrant eutardigrades from homothermic springs on Disko Island, West Greenland. In: D.R. Nelson (Ed.), Proc. Third Int. Symposium on Tardigrada. East Tennessee State University Press, Johnson City, Tennessee, USA: 203-220.

Kristensen, R.M. 1987. Generic revision of the Echiniscidae (Heterotardigrada), with a discussion of the origin of the family. In: R. Bertolani (Ed.), Biology of Tardigrades. Selected Symposia and Monographs, U.Z.I.,1. Mucchi Editore, Modena, Italy: 261-335.

Kristensen, R.M. \& T.E. Hallas. 1980. The tidal genus Echiniscoides and its variability, with erection of the new family Echiniscoididae fam. n. (Tardigrada). Zool. Scripta, 9: 113-127.

Manicardi, G.C. \& R. Bertolani. 1987. First contribution to the knowledge of alpine grassland tardigrades. In: R. Bertolani (Ed.), Biology of Tardigrades. Selected Symposia and Monographs, U.Z.I.,1. Mucchi Editore, Modena, Italy: 177-185.

Maucci, W. 1979. I Pseudechiniscus del gruppo cornutus, con descrizione di una nuova specie (Tardigrada, Echiniscidae). Zesz. Nauk. Uniw. Jagellon., Prace Zool., 25: 107124.

Maucci, W. 1986. Tardigrada. In: Fauna d'Italia, 34. Calderini, Bologna: $388 \mathrm{pp}$.

Pilato, G. 1969. Evoluzione e nuova sistemazione degli Eutardigrada. Boll. Zool., 36: 327-345.

Pilato, G. 1972. Structure, intraspecific variability and systematic value of the buccal armature of eutardigrades. Z. $f$. zool. System. u. Evolutionsforsch., 1: 65-78.

Pilato, G. 1973. L'armatura boccale di alcune specie di Macrobiotus (Eutardigrada). Boll. Accad. Gioenia Sci. Nat. Catania, Ser. 4a, 12: 187-202.

Pilato, G. 1974a. Struttura dell'armatura boccale di alcune specie di Isohypsibius (Eutardigrada). Animalia, 1: 43-58.

Pilato, G. 1974b. Studio su Diphascon scoticum J. Murr. 1905 (Eutardigrada) e alcune specie ritenute ad esso affini. Animalia, 1: 73-88.

Pilato, G. 1975. On the taxonomic criteria of the Eutardigrada. Mem. Ist. ital. Idrobiol., Suppl. 32: 277-303. 
Pilato, G. 1979. Correlation between cryptobiosis and other biological characteristics in some soil animals. Boll. Zool., 46: 319-332.

Pilato, G. 1981. Analisi di nuovi caratteri nello studio degli Eutardigradi. Animalia, 8: 51-57.

Pilato, G. \& M.G. Binda. 1983. Precisazioni sull'apparato buccofaringeo di tipo Diphascon (Eutardigrada). Animalia, 10: 291-302.

Pilato, G., R. Bertolani \& M.G. Binda. 1982. Studio degli Isohypsibius del gruppo elegans (Eutardigrada, Hypsibiidae) con descrizione di due nuove specie. Animalia, 9: 185-198.

Ramazzotti, G. 1977. Note statistiche su una popolazione di Macrobiotus areolatus (Tardigrada). Mem. Ist. ital. Idrobiol., 34: 239-245.
Ramazzotti, G. \& W. Maucci 1982. A history of Tardigrada taxonomy. In: D.R. Nelson (Ed.), Proc. Third Int. Symposium on Tardigrada. East Tennessee State University Press, Johnson City, Tennessee, USA: 3-30.

Schuster R.O., Toftner E.C. \& A.A. Grigarick 1978. Tardigrada of Pope Beach Lake Tahoe, California. The Washmann J. Biol., 35: 115-136.

Wainberg, R.H. \& W.D. Hummon. 1981. Morphological variability of the tardigrade Isohypsibius saltursus. Trans. Am. Microsc. Soc., 100, 1: 21-33.

Zar, J. 1974. Biostatistical analysis. Englewood Cliffs, Prentice Hall, Inc., N.J.: 620 pp. 